\title{
Workplace Incivility and Bullying in the Library: Perception or Reality?
}

\author{
Shin Freedman and Dawn Vreven
}

\begin{abstract}
Recent media reports have increased awareness of workplace incivility and bullying. However, the literature regarding workplace incivility and bullying in academic libraries is under reported and under researched. This study examines the current state of librarians' perceptions on workplace incivility and bullying and evaluates the effects of bullying from organizational and individual perspectives. Bullying was measured based on the librarian's responses to the Negative Acts Questionnaire, including both experienced bullying and witnessed bullying. The authors introduce a conceptual framework to understand the motivating structures, precipitating circumstances, and enabling structures that lead to bullying in the library. A statistical analysis using a regression model revealed several factors that influenced bullying, including a librarian's ethnicity, the number of years worked in the library, the type of institution, and a librarian's academic status. The findings can be useful for discussions of improving workplace climate, increasing retention and recruitment for academic librarians, and helping early career librarians throughout the promotion and tenure processes.
\end{abstract}

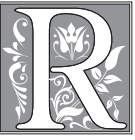

uth Namie and Gary Namie introduced the term "workplace bullying" to the United States in 1998. The World Health Organization defines bullying as: "...a multifaceted form of mistreatment, mostly seen in schools and the workplace. It is characterized by the repeated exposure of one person to physical and/or emotional aggression including teasing, name calling, mockery, threats, harassment, taunting, hazing, social exclusion or rumors." ${ }^{1}$ There are ample examples of bullying in disciplines such as management, ${ }^{2}$ nursing, ${ }^{3}$ and business. ${ }^{4}$ The Workplace Bullying Institute-Zogby study of 2014 reported that 27 percent of U.S. workers have experienced bullying and a further 21 percent have witnessed bullying at work. ${ }^{5}$ In 2002, a European Foundation study reported that bullying is almost three times more likely to occur in the education, social service, and healthcare professions than in any other organizations. ${ }^{6}$ Academic libraries are certainly not immune to workplace bullying and can also be prime settings for incivility and mobbing. ${ }^{7}$ In fact, comparisons indicate that persistent workplace negativity is much higher in U.S. academic libraries than in the general workforce.

Shin Freedman is Head, Scholarly Resources \& Collections at Framingham State University Library, and Dawn Vreven is an Associate Professor in the Psychology Department at Framingham State University; e-mail: sfreedman@framingham.edu,dvreven@framingham.edu. (C) 2016 Shin Freedman and Dawn Vreven, Attribution-NonCommercial (http://creativecommons.org/licenses/by-nc/3.0/) CC BY-NC. 
Sixty-nine percent of U.S. academic librarians experienced at least three negative acts in any six-month period, and nearly 22 percent experienced three negative acts on a weekly or daily basis. Virgina Myers notes that college campuses, “... Once thought to be bastions of collegiality and high-mindedness...turn out to be no more immune to bullying than your average workplace, or your average grade school." ${ }^{8}$ Despite the fact that nearly 20 years ago Hannabuss heralded that "bullying at work is widespread and it is spreading like an epidemic" in the British journal Library Management, ${ }^{9}$ bullying goes almost unnoticed in academic libraries. McAvoy \& Murtagh called workplace bullying the silent epidemic in academia. ${ }^{10}$ This paper seeks to understand the relative silence in library and information science literature on the important topic of bullying in academic libraries.

\section{Bullying, Incivility, Mobbing, and Collegiality}

Lutgen-Sandvik, Tracy, and Alberts assert that even though U.S. researchers have studied a wide variety of negative acts at work, these scholars have given the bullying phenomenon, as conceptualized in international studies, less attention. ${ }^{11}$ She describes some unique features of bullying and claims that adult bullying at work has four specific features: intensity, repetition, duration, and power disparity. First, bullying involves multiple negative acts. ${ }^{12}$ The majority of targets report being subjected to numerous forms of abuse. ${ }^{13}$ Thus, "intensity" specifies the range of different negative acts that targets report. Second, these negative acts must occur frequently, usually weekly or more often. Since bullying is conceptualized as a repetitive "hammering away" at targets, most researchers do not regard one-time incidents as bullying. Third, not only must two or more negative acts occur weekly, they must occur over a period of time-usually a six-month duration - to differentiate bullying from lower-level negativity. ${ }^{14}$ Finally, a power disparity between the perpetrator and the target is central to the definition of bullying. ${ }^{15}$ The majority of definitions for workplace bullying suggest that the target must feel unable to stop or prevent the abuse. That is, in bullying situations, a power disparity either exists at the beginning of bullying or develops over time.

Workplace incivility as a problem separate from bullying was introduced in 1999 by Anderson and Pearson. ${ }^{16}$ Incivility is a general term used to describe behaviors that disregard expected norms. Incivility, bullying, and physical violence lie on a 10-point continuum of organizational disruption according to Gary Namie. ${ }^{17}$ Incivility ranges from 1 to 3 on the continuum, while bullying covers scores of 4 to 9 . Both incivility and bullying are disruptive, differing primarily in the degree of disruption. Porath and Pearson estimated that 98 percent of workers in North America experience incivility, with 50 percent experiencing such conduct at least weekly. ${ }^{18}$ Unchecked rudeness, a form of incivility, is surprisingly common, according to the article. ${ }^{19}$ They posited that uncivil workplace behavior in ongoing coworker interactions is reciprocated with even more severe forms of negativity. ${ }^{20}$

Hecker's 2007 paper was the first published article ${ }^{21}$ about workplace mobbing in academic libraries and included the startling observation that "mobbing takes place in schools, universities and libraries at twice the rate of workplace in general." Hecker distinguishes mobbing from bullying by defining mobbing as "a particularly devastating form of workplace conflict, in which a group in solidarity intentionally creates a hostile work environment for an individual who has been ostracized." The author notes that mobbing, based on Leymann's scholarship, "begins with a triggering unresolved conflict and then develops an enduring, remorseless course which professionally, emotionally and often physically harms the target."

Finally, lack of collegiality in the academic workplace is reported as the key negative influence on workplace satisfaction for faculty. ${ }^{22}$ The critical role that interpersonal 
relationships play in academia creates many opportunities for interpersonal conflicts that may result in noncollegial behavior. ${ }^{23}$ Academia is a particularly vulnerable setting for persistent aggression as a result of the tenure process, which places faculty and staff in very long-term relationships with one another. Researchers have found that the academic environment has a number of organizational and work features that increase the likelihood of hostile interpersonal behaviors. ${ }^{24}$ Hoel and Salin, for example, noted that organizational culture and climate play an important role in the manifestation of hostile behaviors at work. Organizational cultures that damage collegiality are characterized as competitive, adversarial and politicized, with authoritarian leadership that does not tolerate nonconformity. ${ }^{25}$ On the other hand, organizational cultures that are nonconfrontational, indirect, and permissive may create an environment where lack of collegial behavior is implicitly condoned. ${ }^{26}$ As Leah Plocharczyk notes, conflict is inevitable in any working situation. Work-related conflict, if unresolved over time, transforms into personal conflict, which leads to incivility and bullying. Noncollegial organization structures are associated with significant costs, including loss of prized employees, demoralization of staff and impaired staff relations, disruption of operations, harm to the organization's reputation, increased absenteeism, and a decrease in productivity and creativity. Worse yet, even if individual employees leave or new employees are hired, the system still allows negative behaviors to continue. ${ }^{27}$ These are conditions that appear to be contradictory to higher education's notions of civility, the pursuit of academic freedom, and autonomy.

\section{Bullying in the Academic Library}

A broad review of the past 15 years of research reveals that little attention has been given to the existence, causes, and consequences of bullying in the academic library. Only a few articles about bullying in academic libraries have appeared in library and information science literature. ${ }^{28}$

Motin wrote an article titled "Mobbing or Bullying in Libraries" in 2009, in which she reported that the traditional gentleness and service orientation of the librarian has so influenced the conventional perception of libraries that one does not normally think that there is any bullying or mobbing in these places of quiet study and research. As Motin notes, "There is a presumption that libraries exist on a higher plane; that they are places of refuge, bastions of freedom and evidence of civilization at its best." Motin related her personal experience as being the target of bullying and mobbing by supervisors and coworkers and has also witnessed this phenomenon among others. Bullying generates a culture of anxiety, stress, and distrust that impedes the goals of providing the best possible service to patrons and prevents the free flow of ideas and creativity. ${ }^{29}$

A year later, CERL News published an article by Leiding on the scope of mobbing or bullying in the library workplace and how to prevent mobbing in the library workplace..$^{30}$ Also in 2010, Bonnie Osif wrote a review article on workplace incivility and bullying for Library Leadership and Management. ${ }^{31}$ Among a dozen sources, Osif found and reviewed only one blog article that referred to incivility in the academic library. ${ }^{32}$ This is significant because it suggests that bullying, from the perspective of the library, is being overlooked or ignored.

Finally, in 2012, Freedman emphasized the importance of collegiality in an article based on a survey of Massachusetts public higher education librarians. ${ }^{33}$ Freedman distributed a survey to nine academic libraries in a union environment and asked questions about the attitudes and perceptions of librarians and their views on collegiality and its importance in their organizations. Many respondents agreed that collegiality was important, particularly to the function of library work. They also agreed that the definition of collegiality entailed treating each other with respect and fairness; how- 
ever, with regard to interdepartmental relationships, many of those surveyed did not believe that there was open communication or information sharing.

The lack of recent research on bullying in the library coincides with a rapidly changing technological environment coupled with increased attention to age, race, culture, and diversity in the American workplace, all of which may contribute to bullying. The social landscape of American academic libraries has been deeply affected by this rapid change. Because the effects of bullying have severe negative consequences for both institutional integrity and employee satisfaction, and because of the severe negative effects on institutional objectives and outcomes, it is urgent that we address these issues in academia.

\section{Conceptual Framework}

Nielsen's 2013 study on bullying and leadership suggests that the high incidence of bullying and the severe negative effects of this phenomenon present a serious problem with regard to psychosocial safety for many in contemporary working life. ${ }^{34}$ Hence, the identification of factors that influence the occurrence of bullying is of high importance. To summarize and explain the complex organizational antecedents that lead to workplace incivility and bullying, we developed a conceptual model of workplace bullying. The model was adopted from Swedish management scholar Denise Salin's 2003 study $^{35}$ of general workers. Twale and De Luca's 2008 study $^{36}$ of U.S. academics was also used in the development of the model. Three factors - the motivating structures and processes (top left), precipitating circumstances (bottom left), and enabling structures and process (center arrow) - are shown in figure 1.

The structures that motivate bullying are built in to the management style of an institution. One of the motivating structures for bullying in the library is the inequity of rewards and benefits between librarians and teaching faculty. In many institutions, librarians are compensated less, receive fewer benefits, and have less status than teaching faculty. This inequity can lead to dissatisfaction, which in turn encourages uncivil behavior. Unhappy employees may be frustrated and more likely treat coworkers poorly. A second motivating structure is library leadership. Poor leadership negatively impacts professional development. Another factor motivating bullying is the governance structure. In many cases, a librarian's input into the governance process is considered to be less important. Bullying in the library is also motivated by library bureaucracy, particularly in public institutions. Bureaucratic structures that are inflexible and inefficient prevent adaptive change and stifle collaboration. Finally, internal competition among librarians for limited resources has the potential to create conflict that can motivate bullying.

The circumstances that precipitate bullying are work-related conditions or events that encourage uncivil behavior. The shift to electronic and digital platforms has impacted libraries greatly. As more and more courses are being offered online, librarians have been forced to adjust to a new academic environment that requires different services. The demand for online resources from libraries has disrupted the traditional, accepted day-to-day operations in the library. This shift triggers restructuring in the library, where outmoded services or divisions may be eliminated. The threat of such restructuring can make employees feel defensive, setting the stage for bullying. A recent emphasis on value-added services and assessment increases competition and resentment among librarians. The focus has become one in which a library's value is determined by external agents (such as student satisfaction), rather than internal, library-centered metrics. This change in institutional alignment can provoke fear in some workers, leading to an increased risk for bullying. Finally, the demographics of the student population and the population of librarians have been diverging. In particular, young people are using technology in ways that older librarians may not be familiar with. Students may 
expect library services to be delivered in ways that librarians without much technical experience are not comfortable with. This divergence can leave librarians feeling isolated and insecure, leading to more easily provoked defensive bullying.

The enabling structures and processes have particular significance because they act as both a foundation for bullying and a filter through which structural aspects of the work environment are channeled. The existence or lack of enabling factors may prevent or promote bullying behavior. ${ }^{37}$ The enabling structure of bullying in the library includes tension between librarians and teaching faculty and/or administration, the changing and often marginalized role of librarians in the learning and teaching processes, demands and pressures of providing library services ubiquitously in a digital environment, and the academic library culture that may adapt quickly or not, which will impact directly and indirectly. If these enabling structures were eliminated, then incivility and bullying may be prevented.

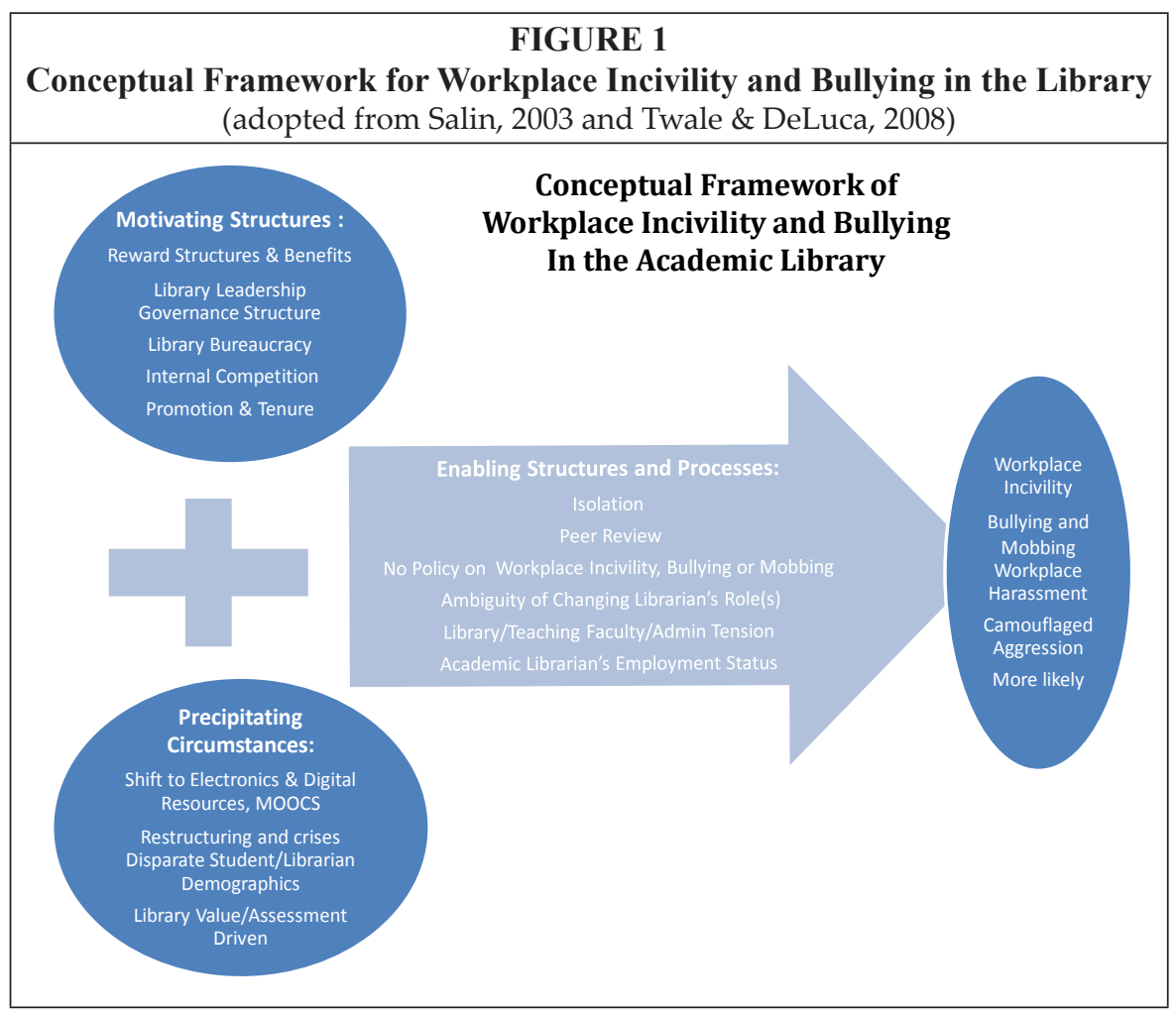

\section{Purpose}

The aim of this study is to assess the prevalence of workplace incivility and bullying among academic libraries in the United States and to compare their prevalence with other U.S. workplace studies. Demographic variables such as gender, ethnicity, years worked in the library, and job status (administrator or librarian) were incorporated to determine what factors (if any) predicted the experience of negative acts in the library workplace environment. The overall goal of the work is to identify factors associated with bullying in the academic library to raise awareness and to offer areas of focus for preventing bullying in the academic workplace. 


\section{Method}

An online survey was created using Survey Monkey and distributed to two library listservs, the Association of College and Research Libraries' College Libraries (ACRL) Section (Collib-L, $\mathrm{n}=2,873$ ) and the Association for Collections and Technical Services leaders and members (ALCTSLEADERS, $\mathrm{n}=500$ ). The authors used the Bergen Research Institute (BRI) Negative Acts Questionnaire-Revised (NAQ-R) instrument by Einarsen, Raknes, Mattiesen and Hellesoy and Hoel (1999). ${ }^{38}$ The instrument is made available for free in exchange for the data at the end of the project. The NAQ-R instrument contains 22 questions rated on a five-point scale from 1 (never) to 5 (daily) and is a recognized statistically reliable and valid instrument used by academicians. The Bergen Bullying Research Group (BBRG) website is: www.uib.no/en/rg/bbrg/44045/ naq. In addition, this instrument was recommended by the U.S.-based leading bullying research organization, The Workplace Bullying Inc., which compiles the WBI survey data that was summarized in our legislation of the Healthy Workplace Bill.

The NAQ-R is one of the most widely used instruments for assessing bullying at work. The instrument was selected because it focused only on behaviors and reactions while specifically avoiding the use of the term "bullying." The survey asked respondents whether, in the last six months, s/he had been subjected to any of 22 particular examples of negative behavior or acts from a coworker. The instrument is designed to measure three types of negative acts: Work-Related (W-R), Person-Related (P-R), and Physically Intimidating (P-I) behaviors. Two additional questions asked how frequently the respondent had been bullied in the last six months, if at all, or if the respondent had witnessed others being bullied in the last six months. These two questions introduce the word "bullying" for the first time in the survey. Additionally, demographic questions were added to the survey.

The data collected from Survey Monkey were reported in a basic frequency table. Data were further analyzed using Qualtrics and SPSS version 21 to generate regression analysis and instrument validity tests.

\section{Participants Profile}

Data were collected in the last two weeks of March 2014 from a population of 3,373 librarians and library staff who registered on two listservs. The sample size was 414 (response rate $=11.9 \%$ ). The parameters for this study limited the survey to members of the ACRL, of which one of the largest public service groups was chosen, Collib-L and the other in the technical service area, Alctsleaders. Although they overlap, our goal of choosing these two listservs was to reach an audience as wide as possible from the public and the technical services.

\section{Demographic Characteristics}

Regarding professional library work experience, approximately one-third of the respondents $(33.8 \%, \mathrm{n}=140)$ had zero to three years of work experience in their current positions, and just over one-quarter $(26.6 \%, \mathrm{n}=110)$ had more than 4 to 7 years of experience in their current positions. All in all, 40 percent $(n=164)$ of the respondents fell into the category of mid- to mature-career librarians.

A majority of respondents $(81.7 \%, \mathrm{n}=331)$ were female; male respondents were fewer than one in five $(18.3 \%, \mathrm{n}=74)$. In terms of the types of institutions they represent, 39.6 percent $(n=164)$ were from private institutions and 56.7 percent $(n=235)$ from public. The ethnicity of the respondents included 88 percent White/Caucasian, with 12 percent from minority groups consisting of 3.2 percent Asians, 1.5 percent Latinos, 4.2 percent Black American, and 2.7 percent of mixed heritage. The majority of the respondents were veteran academic librarians, with 34.3 percent having 21 years or more 
of experience working at libraries in institutions of higher education. The educational background of the study respondents shows that they were well educated: 7.8 percent $(n=31)$ were doctoral degree holders (PhD, EdD, or JD degrees); and 36.7 percent $(n=$ 146) had a second masters' degree besides the required master's degree in Library and Information Sciences $(95.5 \%, \mathrm{n}=380$; see table 1$)$. The individual questions included on the NAQ-R appear in table 2.

\begin{tabular}{|c|c|c|}
\hline \multicolumn{3}{|c|}{$\begin{array}{c}\text { TABLE } 1 \\
\text { Descriptive Statistics for Demographic Information }(\mathrm{N}=414)\end{array}$} \\
\hline Administrative Status & $\mathbf{N}$ & $\%$ of Sample \\
\hline Administrative & 78 & 18.8 \\
\hline Non Administrative (Librarian) & 327 & 79 \\
\hline Missing & 9 & 2.2 \\
\hline Education & $\mathbf{N}$ & $\%$ of Sample \\
\hline MLS or Related Degree & 250 & 60.4 \\
\hline MLS and Second Master's Degree & 126 & 30.4 \\
\hline Ed.D or Ph.D & 17 & 4.1 \\
\hline Other/Missing & 21 & 5.1 \\
\hline Ethnicity & $\mathbf{N}$ & $\%$ of Sample \\
\hline White/Caucasian & 353 & 85.3 \\
\hline Black American & 17 & 4.1 \\
\hline Latino/Latina/Hispanic & 6 & 1.4 \\
\hline Asian American/Pacific Islander & 13 & 3.1 \\
\hline Mixed Heritage & 11 & 2.7 \\
\hline Other/Missing & 14 & 3.4 \\
\hline Faculty Status & $\mathbf{N}$ & $\%$ of Sample \\
\hline Faculty Tenure Track & 159 & 38.4 \\
\hline Faculty, No Tenure Available & 77 & 18.6 \\
\hline Not Faculty No Tenure Available & 134 & 32.4 \\
\hline Tenure Only, No Faculty Status & 10 & 2.4 \\
\hline Other/Missing & 34 & 8.2 \\
\hline Gender & $\mathbf{N}$ & \% of Sample \\
\hline Female & 331 & 80.0 \\
\hline Male & 74 & 17.9 \\
\hline Other/Missing & 9 & 2.2 \\
\hline Type of Library & $\mathbf{N}$ & \% of Sample \\
\hline Public 4 Year & 207 & 50.0 \\
\hline Public 2 Year & 28 & 6.8 \\
\hline Private 4 Year & 157 & 37.9 \\
\hline Private 2 Year & 7 & 1.7 \\
\hline Other/Missing & 15 & 3.6 \\
\hline
\end{tabular}




\begin{tabular}{|l|c|c|}
\hline \multicolumn{3}{|c|}{ TABLE 1 } \\
Descriptive Statistics for Demographic Information (N=414) \\
\hline Years Worked in a Library & N & \% of Sample \\
\hline 0-3 Years & 34 & 8.2 \\
\hline 4-7 Years & 62 & 15.0 \\
\hline 8-12 Years & 68 & 16.4 \\
\hline 13-20 Years & 108 & 26.1 \\
\hline 21 or More Years & 142 & 34.3 \\
\hline Other/Missing & 0 & 0 \\
\hline
\end{tabular}

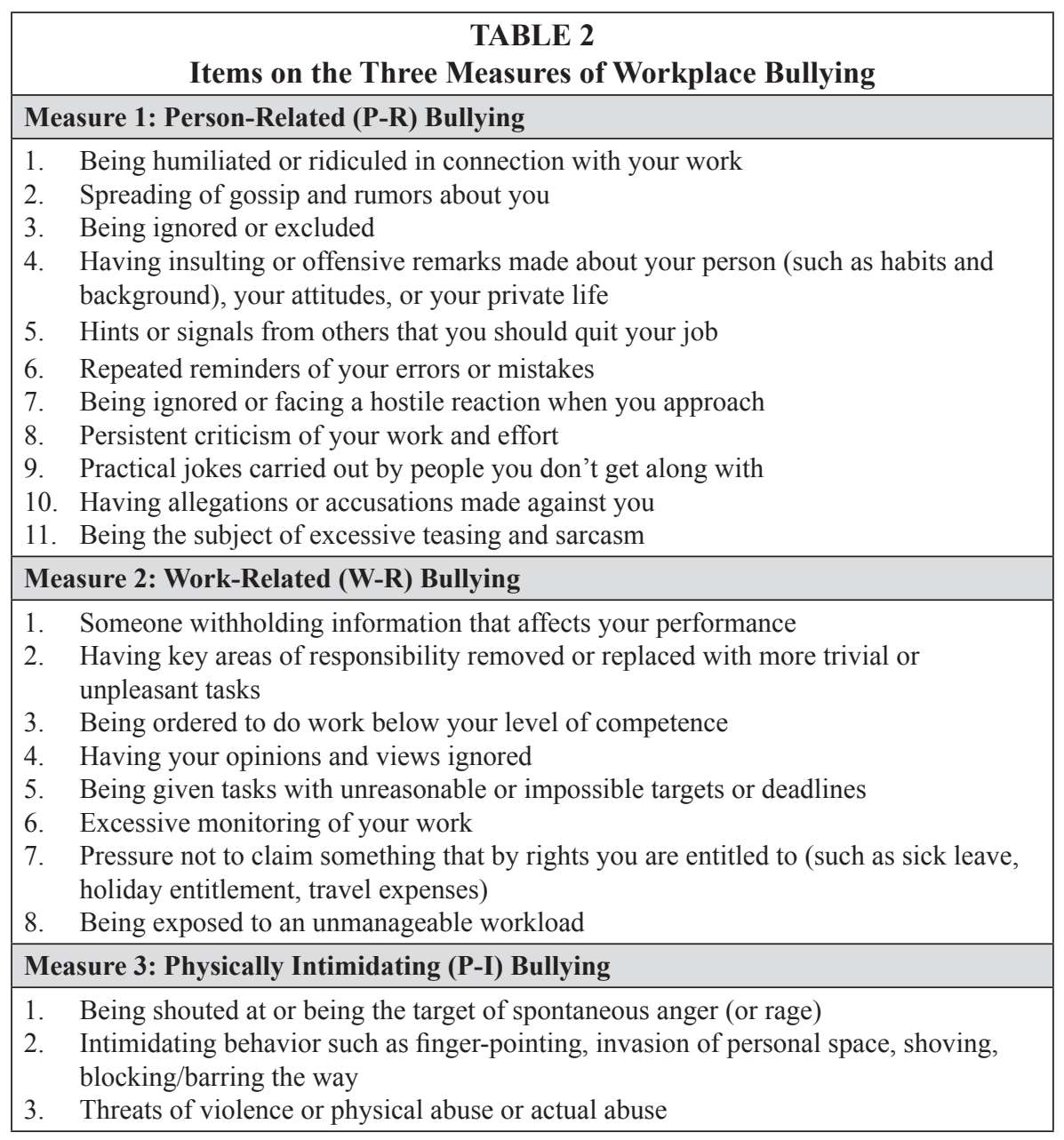

\section{Measures}

The NAQ-R contains three measures of negative acts. The first measure, PersonRelated (P-R) negative acts, consisted of 11 items asking respondents to rate the frequency with which they had experienced various acts of personal bullying. Respondents were asked to rate the frequency, during the past six months, that they 
had been subjected to a specific negative act in the workplace. Frequency responses were given on a 1 to 5 scale, with $1=$ never, 2 = now and then, $3=$ monthly, $4=$ weekly, and $5=$ daily. Items on this measure included statements such as "Being the subject of excessive teasing and sarcasm," "Being ignored or facing a hostile reaction when you approach," and "Having allegations or accusations made against you." A single summary score was calculated for each respondent by summing his or her responses to the 11 individual items. Thus, scores on the P-R scale could range from 11 to 55. Cronbach's alpha is a widely used measure of the reliability of a set of test items. Alpha is calculated to determine the degree to which the questions on a particular test measure the same underlying concept, and so it is a measure of internal consistency. The value of alpha can range from 0 to 1 , with larger numbers indicating better reliability. Alpha values of .70 or greater are considered acceptable. The alpha value for the P-R scale, calculated from the current sample, was .92, indicating high reliability for the scale.

Similarly, a second measure of Work-Related (W-R) bullying consisted of responses to 8 items. Again, individuals were asked to rate the frequency, over the past six months, that they had been subjected to specific negative acts from a coworker. The items on the Work-Related scale, however, all made reference to the effect of bullying on work performance. Example items include "Excessive monitoring of your work," "Being given tasks with unreasonable or impossible targets or deadlines," and "Pressure not to claim something which by right you are entitled to (such as sick leave, holiday entitlement, travel expenses)." Scores on the W-R scale ranged from 8 to 40 . Cronbach's alpha for the W-R scale was .88, again indicating high reliability for the scale.

Finally, a third measure of Physically Intimidating (P-I) consisted of responses to three items. Respondents again rated the frequency, over the past six months, that they had been subjected to the following negative acts from a coworker: "Being shouted at or being the target of spontaneous anger (or rage)," "Intimidating behavior such as finger-pointing, invasion of personal space, shoving, blocking/barring the way," and "Threats of violence of physical abuse or actual abuse." Scores on the P-I scale ranged from 3 to 15. Cronbach's alpha for the P-I scale was .70, indicating good reliability for the scale.

\section{Analyses}

Multiple regression analyses were conducted to examine the relationship between various predictor variables and Person-Related negative acts, Work-Related negative acts, and Physically Intimidating negative acts. The regression model examined whether administrative status (librarian or administrator), ethnicity, gender, type of library of employment (two- or four-year institution, public or private), academic status (faculty or staff and tenure availability), and the number of years worked in a library predicted Person- Related, Work-Related, or Physically Intimidating negative acts. Because the predictor variables were categorical, the regression model required a "reference" or "standard" group for each factor. Thus, a set of $k-1$ dummy variables was created for each factor, leading to the development of 16 predictor variables (1 predictor for administrative status with librarians as the reference group, 1 predictor for gender with males as the reference group, 4 predictors for ethnicity with Caucasian/White as the reference group, 3 predictors for library type with "public 4-year" as the reference group, 3 predictors for faculty status with "tenure-track faculty" as the reference group, and 4 predictors for years worked in the library with " 21 or more years" as the reference group..$^{39}$ 


\begin{tabular}{|l|c|c|}
\hline \multicolumn{3}{|c|}{ TABLE 3 } \\
\multicolumn{3}{|c|}{ Predictors for Person-Related (P-R) Negative Acts } \\
\hline & $\beta$ & $p$ \\
\hline Administrator vs. Librarian & -.085 & .141 \\
\hline Gender: Male vs. Female & .016 & .768 \\
\hline Ethnicity: Black American vs. White/Caucasian & .069 & .209 \\
\hline Ethnicity: Latino(A)/Hispanic vs. White/Caucasian & .067 & .233 \\
\hline Ethnicity: Asian American/Pacific Islander vs. White/Caucasian & .124 & $.032 *$ \\
\hline Ethnicity: Mixed vs. White/Caucasian & .008 & .891 \\
\hline Library Type: Public 2 Year vs. Public 4 Year & -.031 & .586 \\
\hline Library Type: Private 4 Year vs. Public 4 Year & -.044 & .472 \\
\hline Library Type: Private 2Year vs. Public 4 Year & -.071 & .208 \\
\hline Status: Faculty, No Tenure Available vs. Faculty Tenure Track & -.083 & .184 \\
\hline Status: Not Faculty, No Tenure Available vs. Faculty Tenure Track & .045 & .473 \\
\hline Status: Tenure Only vs. Faculty Tenure Track & -.114 & $.049 *$ \\
\hline Years In Library: 0 to 3 vs. 21 or More & .013 & .834 \\
\hline Years In Library: 4 to 7 vs. 21 or More & .149 & $.019 *$ \\
\hline Years In Library: 8 to 12 vs. 21 or More & .079 & .211 \\
\hline Years In Library: 13 to 20 vs. 21 or More & -.046 & .465 \\
\hline$* p \leq .05$ & & \\
\hline
\end{tabular}

\section{Results}

The regression model significantly predicted Person-Related negative acts, $F(16,315)$ $=1.76, P=.036$. The $R^{2}$ value for Person-Related negative acts was .082 , indicating that around 8 percent of the variance in Person-Related scores was accounted for by the model. Table 3 shows the standardized $\beta$ coefficients and $P$-values for the predictors for Person- Related negative acts. Asian ethnic identification was significantly related to increased P-R acts compared to the White/Caucasian reference group, $P=.032$. Work length in a library for 4-7 years was also significantly related to increased negative acts compared to the reference work length of 21 or more years, $P=.019$. Finally, working at an institution that offers tenure but not faculty status was a significant predictor of fewer $P$-R negative acts compared to institutions offering tenure-track faculty status, $P=.049$.

The regression model also significantly predicted Work-Related negative acts, $F$ $(16,315)=3.22, P<.001$. The $R^{2}$ value for Work-Related acts was .140 , indicating that 14 percent of the variance in Work-Related scores was accounted for by the model. Table 4 shows the standardized $\beta$ coefficients and $P$-values for the predictors. Asian and Black American ethnic identification was significantly related to increased W-R negative acts relative to the White/Caucasian reference, $P=.007$ and .028 , respectively. As before, work length in a library for 4-7 years was also significantly related to increased negative acts compared to the reference work length of 21 or more years, $P=$ .002. Finally, administrators reported significantly less $W-R$ than librarians, $P=.006$.

Last, the regression model significantly predicted Physically Intimidating negative acts, $F(16,315) P=2.4, P=.002$. The $R^{2}$ value for Physically Intimidating acts was .109 , indicating that about 11 percent of the variance in Physically Intimidating scores was accounted for by the model. Table 5 shows the standardized $\beta$ coefficients and $P$-values 


\begin{tabular}{|l|c|c|}
\hline \multicolumn{3}{|c|}{ TABLE 4 } \\
\hline & $\beta$ & $p$ \\
\hline Administrator vs. Librarian & -.155 & $.006^{* *}$ \\
\hline Gender: Male vs. Female & .059 & .274 \\
\hline Ethnicity: Black American & .143 & $.007 * *$ \\
\hline Ethnicity: Latino(a)/Hispanic vs. White/Caucasian & .027 & .618 \\
\hline Ethnicity: Asian American/Pacific Islander vs. White/Caucasian & .123 & $.028^{*}$ \\
\hline Ethnicity: Mixed vs. White/Caucasian & .004 & .938 \\
\hline Library Type: Public 2 Year vs. Public 4 Year & -.030 & .580 \\
\hline Library Type: Private 4 Year vs. Public 4 Year & -.037 & .534 \\
\hline Library Type: Private 2 Year vs. Public 4 Year & -.030 & .580 \\
\hline Status: Faculty, No Tenure Available vs. Faculty Tenure Track & -.107 & .075 \\
\hline Status: Not Faculty, No Tenure Available vs. Faculty Tenure Track & .106 & .086 \\
\hline Status: Tenure Only vs. Faculty Tenure Track & -.065 & .244 \\
\hline Years in Library: 0 to 3 vs. 21 or More & .029 & .612 \\
\hline Years in Library: 4 to 7 vs. 21 or More & .190 & $.002 * *$ \\
\hline Years in Library: 8 to 12 vs. 21 or More & .089 & .142 \\
\hline Years in Library: 13 to 20 vs. 21 or More & .052 & .395 \\
\hline$*$ p $\leq .05, * *$ p $\leq .01$. & & \\
\hline
\end{tabular}

for the predictors. Asian ethnic identification was again significantly related to increased $\mathrm{P}-\mathrm{I}$ acts relative to the White/Caucasian reference, $P=.009$. As with the previous measures, work length in a library for 4-7 years was also significantly related to increased negative acts compared to the reference work length of 21 or more years, $P=.003$. Administrators reported significantly fewer P-I acts than librarians, $P=.010$, and those with faculty status but not tenure reported fewer acts than tenure- track faculty, $P=.043$.

\section{Single-Item Analyses: Most Frequent Workplace Negative Acts by Item}

Table 6 below summarizes responses to the four items associated with the greatest frequency of endorsement. Specifically, the responses of those who experienced a negative act either "now and then," "monthly," "weekly," or "daily" were combined and compared with those who responded "never." More than 60 percent of respondents reported three of the negative acts occurring at least "now and then" ("someone is withholding information that affects your performance," "being ignored or excluded," and "having your opinions and views ignored"), compared with 29.5 percent of respondents who reported that these acts "never" occurred. One negative act, "being exposed to an unmanageable workload," had an almost equal number of "never (44.4\%)" and the combined frequency of "daily," "weekly," "monthly," and "now and then" responds (46.6\%). The 9 percent accounts for missing data in table 6.

Finally, the last two questions explicitly addressed Experienced Bullying and Witnessed Bullying. Specifically, respondents were asked to "State whether you have been bullied at work during the last six months" and were also asked "Have you seen others being subjected to bullying at your workplace during the last six months?" 


\begin{tabular}{|l|c|c|}
\hline \multicolumn{3}{|c|}{ TABLE 5 } \\
\hline \multicolumn{3}{|c|}{ Predictors for Physically-Intimidating (P-I) Negative Acts } \\
\hline & $\beta$ & $p$ \\
\hline Administrator vs. Librarian & -.147 & $.010^{* *}$ \\
\hline Gender: Male vs. Female & .028 & .613 \\
\hline Ethnicity: Black American vs. White/Caucasian & .019 & .721 \\
\hline Ethnicity: Latino(A)/Hispanic vs. White/Caucasian & .038 & .494 \\
\hline Ethnicity: Asian American/Pacific Islander vs. White/Caucasian & .149 & $.009^{* *}$ \\
\hline Ethnicity: Mixed vs. White/Caucasian & -.027 & .620 \\
\hline Library Type: Public 2 Year vs. Public 4 Year & -.002 & .971 \\
\hline Library Type: Private 4 Year vs. Public 4 Year & -.028 & .635 \\
\hline Library Type: Private 2Year vs. Public 4 Year & -.072 & .196 \\
\hline Status: Faculty, No Tenure Available vs. Faculty Tenure Track & -.124 & $.043 *$ \\
\hline Status: Not Faculty, No Tenure Available vs. Faculty Tenure Track & .023 & .712 \\
\hline Status: Tenure Only vs. Faculty Tenure Track & -.099 & .084 \\
\hline Years In Library: 0 to 3 vs. 21 or More & .005 & .938 \\
\hline Years In Library: 4 to 7 vs. 21 or More & .187 & $.003^{* *}$ \\
\hline Years In Library: 8 to 12 vs. 21 or More & .065 & .294 \\
\hline Years In Library: 13 to 20 vs. 21 or More & .010 & .866 \\
\hline$*$ p $\leq .05, * *$ p $\leq .01$. & & \\
\hline
\end{tabular}

Responses were given on a 1 to 5 scale for both questions, with $1=$ "No," 2 = "Yes, but only rarely," 3 = "Yes, now and then," " 4 = Yes, several times per week," and $5=$ "Yes, almost daily." The data were analyzed separately for administrators and librarians. Table 7 outlines Experienced Bullying (EB) and Witnessed Bullying (WB) by administrative status. Twenty-eight percent of administrators responded "Yes" to a personal bullying experience, compared to 43 percent of librarians in response to Experienced

\begin{tabular}{|c|c|c|c|c|}
\hline \multicolumn{5}{|c|}{$\begin{array}{c}\text { TABLE } 6 \\
\text { Experienced Negative Acts/Behaviors by Frequency }\end{array}$} \\
\hline Type & Negative Acts/Behaviors & $\begin{array}{l}\text { Percent } \\
\text { "Never" } \\
\text { Responses }\end{array}$ & $\begin{array}{l}\text { Percent "Now and } \\
\text { Then," "Monthly," } \\
\text { "Weekly," and "Daily" } \\
\text { Responses Combined }\end{array}$ & $\begin{array}{l}\text { Percent } \\
\text { Missing }\end{array}$ \\
\hline W-R & $\begin{array}{l}\text { Someone is withholding } \\
\text { information that affects } \\
\text { your performance }\end{array}$ & 29.5 & 63.5 & 7 \\
\hline P-R & Being ignored or excluded & 29.5 & 63.5 & 7 \\
\hline W-R & $\begin{array}{l}\text { Having your opinions and } \\
\text { views ignored }\end{array}$ & 28.3 & 62.9 & 8.9 \\
\hline W-R & $\begin{array}{l}\text { Being exposed to an } \\
\text { unmanageable workload }\end{array}$ & 44.4 & 46.6 & 8.9 \\
\hline
\end{tabular}




\section{TABLE 7}

Experienced and Witnessed Bullying for Administrators vs. Librarians (Administrators $N=71$, Librarians $N=299$ )

State whether you have been bullied at work over the last six months.

\begin{tabular}{|l|c|c|}
\hline Response & Admin. \% & Librarians \% \\
\hline No & 71.8 & 56.9 \\
\hline Yes, but only rarely & 14.1 & 15.4 \\
\hline Yes, now and then & 9.9 & 19.1 \\
\hline Yes, several times per week & 2.8 & 6.4 \\
\hline Yes, almost daily & 1.4 & 2.3 \\
\hline
\end{tabular}

Have you seen others being subjected to bullying at your workplace during the last six months?

\begin{tabular}{|l|c|c|}
\hline Response & Admin. \% & Librarians \% \\
\hline No & 53.5 & 45.8 \\
\hline Yes, but only rarely & 14.1 & 19.4 \\
\hline Yes, now and then & 23.9 & 20.1 \\
\hline Yes, several times per week & 7.0 & 9.0 \\
\hline Yes, almost daily & 1.4 & 5.7 \\
\hline
\end{tabular}

Bullying at work. Further, almost 46 percent $(n=33)$ of administrators witnessed bullying of others, while 54 percent $(n=162)$ of librarians reported witnessing bullying done to others. These findings suggest a gap in bullying perception between library administrators and librarians about witnessed bullying and experienced bullying. Specifically, administrators report experiencing bullying much less than librarians, but the rates of witnessing others being bullied is about the same in the two groups.

\section{Discussion and Conclusions}

This study sought to assess the prevalence of workplace incivility and bullying in the library and to identify factors affecting such negative behaviors using the conceptual framework presented in figure 1 as a lens to understand the motivating, triggering, and enabling structures and processes. The regression analyses revealed several factors that reliably predicted exposure to negative behaviors.

One of these factors was ethnicity. Importantly, the representation of minority respondents in the current study closely matched that of the 2012-2013 Association of Research Libraries study, ${ }^{40}$ which reported minority composition as follows: Black American, 4.3 percent $(n=384)$; Hispanic/Latino, 2.8 percent $(n=249)$; and Asian, 7.4 percent (see table 3). Asians and Black Americans reported higher rates of WorkRelated negative acts than other ethnicities. For Person-Related negative acts, Asians and Latinos reported much higher exposure than Black Americans. For Physical Intimidation, Asians reported higher exposure than other ethnicities. These findings are consistent with Duffy and Sperry's identification of "being different" as one of the triggering events of bullying. As Duffy and Sperry note, "Employees/workers who are outsiders and who are different from the cultural norm are more likely to be mobbed than those who are cultural insiders" and "Such outsiders include those whose gender, race, sexual identity are different from the dominant identities within the organization." ${ }^{41}$ Damasco and Hodges' 2012 study $^{42}$ of the tenure and promotion experiences of 
academic librarians of color reached similar conclusions, in which minority librarians not only experienced "implicit and explicit racism" throughout their professional lives but endured difficult circumstances through the tenure and promotion process. These outcomes are consistent with decisions about promotion and tenure being an enabling process for bullying based on race or ethnicity.

A second factor that reliably predicted exposure to negative behavior was the number of years worked in the library. Librarians who had worked in the library 4-7 years reported significantly more exposure to negative acts than those who had worked either fewer or more years. The significance of this timeframe is that most librarians who have faculty status seek reappointment, promotions, and/or tenure during this time. Considering the fact that 60 percent of the respondents had a combination of faculty status, tenure status, and/or full faculty and tenure status, the 4- to 7-year period is a crucial time for promotion and tenure in academia. This study found significantly more exposure to P-R, W-R, and P-I negative acts during the first 4 to 7 years as compared to those who had worked in a library for 21 or more years. Given how critical this timeframe is for professional development and advancement, being bullied during this time in one's career can have long-lasting negative effects, both personally and professionally.

Overall, our study's finding that withholding information was the most frequent type of bullying is consistent with that of Hoel and Cooper's 2000 study, $^{43}$ which indicates that the most common bullying behavior by frequency in the workplace was "someone withholding information which affects your performance." However, the current study also revealed two additional high-frequency negative acts: "Being ignored or excluded" and "Having your opinions and views ignored." These combined three negative acts account for 68 percent of incidents - more than twice the rate of the "never" happened response which was at 31 percent in table 6 . Those who experience workplace negative behaviors by "being ignored or excluded" are often professionally distressed by this treatment. Being ignored or excluded implies that one is incompetent and/or not important enough to be in the group. This situation invokes negative personal and sociocultural consequences. Being ignored by colleagues and coworkers amounts to a "kiss of death" experience in academe, particularly because individual competency and expertise is held in high regard.

Administrative status also reliably predicted exposure to negative acts. Library administrators reported significantly less exposure to W-R and P-I negative acts than librarians. As for overall actual bullying experiences, 40 percent $(n=148)$ reported Experienced Bullying (EB) and 53 percent $(n=196)$ have Witnessed Bullying (WB) done to others. Library administrators reported considerably less EB $(28 \%)$ than librarians (43\%); however, more librarians responded $(54 \%, \mathrm{n}=161)$ that they experienced WB than the administrators $(46 \%, \mathrm{n}=33)$. These findings suggest a gap in bullying perception between library administrators and librarians. The discrepancy in bullying reality and expectations across different job categories of academic librarians can serve as a focus of campuswide discussions on the challenges and opportunities of library leadership and management. At the same time, this finding surprised us the most because this suggests that library administrators had the chance to intervene bullying in action. This result is a clear example of how library leadership and, in particular, avoiding confrontation are motivating structures for bullying. The reasons library administrators fail to address witnessed workplace incivility and bullying is for future consideration of research.

In summary, more librarians than library administrators, irrespective of their academic status, institution type, and gender, witnessed bullying (WB) done to others. Experienced bullying was highest among librarians with a nonwhite ethnic background 
librarians; the lowest EB was among those with a white ethnic background. Finally, those working at 2-year institutions reported more EB (58\%) those at 4-year institutions (38\%).

While no one would deny the detrimental impact of bullying on an individual target, what is the impact on an organization? Librarians with faculty and tenure status have a long-standing relationship with one another. Conflict and aggression may begin slowly but last for a long time. Once conflict escalates, incivility and noncollegial behavior result. The longer such behavior is permitted, the more likely it is that other colleagues will be drawn into the situation. The impact on student retention may also be negatively affected by the staff, faculty, and librarians in the academia.

On a different note, although this study did not solicit any comments, the authors received informal feedback from some survey participants via e-mail. For example, one participant wrote that "I was on the receiving end of workplace bullying in my previous job 4 years ago which directly led to my departure"; "...It took me until last year to realize that I had experienced bullying"; "...If I had been able to identify the situation correctly at the time, I would have been less of a victim." These comments emphasize, in a qualitative way, the importance of awareness and prevention of workplace bullying.

In conclusion, this study indicates that workplace bullying happens in the library irrespective of the academic status and employment status in the academy. Whether librarians have faculty and tenure status, faculty status only, tenure status only, or simply staff-member status, 24 percent of the respondents reported that bullying happens frequently-daily and weekly. Among ethnic minority librarians, Asians and Black Americans experience more negative behaviors in academic libraries of higher education at a time in their careers when reappointment, promotion, and tenure processes start during a librarian's fourth through seventh years of employment. The findings may strain the conventional perception of academic libraries as safe, quiet, congenial spaces. In contrast, the results of the current study clearly show that workplace bullying exists in the academic library. The first step in addressing workplace bullying in the library is to acknowledge its prevalence.

\section{Limitations}

This study has several limitations. First, this study is limited to the librarians who were members of two listservs. Second, participants were asked to recall negative behaviors/ acts that occurred for the last six months based on the NAQ-R questionnaires. We did not solicit any other comments or narratives. Third, it is possible that those librarians who had experiences with workplace bullying were more motivated to participate in the study. However, the survey instrument was designed so that the concept of workplace bullying was not introduced until the last two questions of the survey. Finally, the current study did not explicitly address workplace mobbing as opposed to other types of bullying in the library.

\section{Recommendations}

A bullying-free future starts with acknowledgment of less-than-ideal workplaces and organizations. One of the most daunting problems is the failure to acknowledge and repair the mistakes at the individual, group, or organizational level. The attitude from an organizational perspective that "if something is not acknowledged, it's as if it never happened at all" 44 is simply untenable if we are ever to create positive, bullyfree environments for our librarians and library administrators to thrive and to fully achieve institutional goals. One recommendation to deal with this problem is that library administrators initiate an organizational climate survey to assess the current environment and take corrective actions as needed. 
Based on the results of this work, we recommend the establishment of a policy addressing workplace incivility and bullying for faculty, administrators, librarians, library staff members, and general universitywide staff. A recent example of such a policy comes from the University of Wisconsin, Milwaukee campus, which initiated "Anti-Bullying Policy" for faculty members (http://www4.uwm.edu/secu/docs/faculty/2901_Code_of_Co_ct_04_25_13.pdf).

Campus-initiated or library-initiated conversations on workplace incivility, bullying, and mobbing need to be encouraged. Due to the alarming rate and cost of workplace incivility, recent grassroots movements that advocate civility in the workplace have stimulated universities to develop and execute civility initiatives on several campuses including Central Florida University, Loyola University, Penn State University, Oregon State University, ${ }^{45}$ State University of New York, and University of Maryland. These initiatives are excellent examples of approaches to prevent workplace bullying, incivility, and mobbing. Lack of collegiality, incivility, and workplace bullying and mobbing must be acknowledged, voiced, and considered with greater importance on campuses.

Finally, to our knowledge, this is the first quantitative study of workplace bullying in the library. Future research using a qualitative method could use the current data as a benchmark to provide deeper insights into workplace bullying.

\section{Acknowledgements}

Authors would like to thank Ms. Beth Stahr for her contribution to this study. We are grateful for suggestions from anonymous reviewers on our earlier manuscript. In addition, thanks are extended to James M. Freedman and Dr. Timothy Maciel for their support and encouragement throughout the completion of this manuscript. 


\section{Study of Workplace Civility Perceptions among Academic Librarians}

Dear Colleague

We'd like to invite you to participate in a survey, Study of Workplace Civility Perceptions among Academic Librarians. The intent of this study is to measure perceived exposure to bullying and incivility in the workplace.

The investigators acknowledge the Bergen Bullying Research Group and researchers Einarsen and Stale who developed the NAQ and NAQ-R instruments used to create this survey.

The survey will take about 15 minutes to complete.

Your participation is voluntary and there are no consequences associated with not participating in this study. A participant may withdraw from the survey at any time without penalty. There is no known risk to participating in this study. All responses and information will be confidential. You wil not be identified in any report on this study. Data gathered will be presented without identifying information. Electronic copies of the survey data will be kept in a secured locked file cabinet in one of the researchers' office drawer.

There is no direct benefit for the survey participants. However, there is more general benefit to the profession by learning more about the relationships affecting workplace dynamics in the academic library. Your response will help us better understand the ecology of the workplace, and may contribute to facilitating professional development of academic librarians.

If you have any questions about the study or procedures, please feel free to contact Principal Investigators, Shin Freedman, Librarian at FSU and Beth Stahr, Professor and Librarian at Southeastern Louisiana University. Shin Freedman may be contacted sfreedman@framingham.edu, or 508.626.4666. Beth Stahr's contact information: bstahr@selu.edu or 985.549.5056. For information regarding your rights as a research participant, you may contact Chair of the Institutional Review Board at Framingham State University, Dr. Marian Cohen, (508) 626-4877 or the Chair of the Institutional Review Board at Southeastern Louisiana University at 985-549-2077.

By proceeding to complete the survey, you are indicating that you have read and understood the information above, and are agreeing to participate.

\section{In what type of library do you work?}

I. Public, Academic (4 year)

I. Public, Academic (2 year)

I. Private, Academic (4 year)

II Private, Academic (2 year)

II. Other (please explain)

\section{Do you work full-time?}

II) Yes

II No

II. Other (please explain)

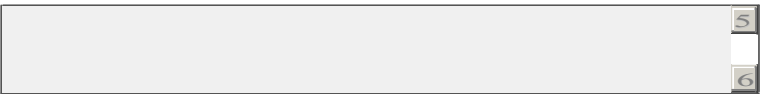

\section{What is your current status ?}

I. Faculty with tenure or tenure-track status

II Faculty status, no tenure or tenure track status (i.e., instructor)

II Tenure only, no faculty status

I. Neither faculty or tenure/tenure-track status

I. Other (please explain) 
4. How long have you worked in a library?

il. $0-3$ years

1. $4-7$ years

1. $8-12$ years

I. 13-20 years

17. 21 or more years

\section{How long have you worked in your current position?}
I1) 0-3 years
1. 4-7 years
I] $8-12$ years
il. 13-20 years
1. 21 or more years

\section{What is your job title?}

\section{What is your gender?}
1. Male
1. Female

\section{What is your ethnic background?}
I. African American/Black
1. Asian American/Pacific Islander
II. American Indian
1. Latino/Latina/Hispanic
II. White/Caucasian
1. Mixed Heritage

9. What advanced degrees, if any, do you hold? Check all that apply.
e "Library degree" (MLS, MLIS, MSIS, MSLS, MIS, MSLIS, MALS, MSI, MALIS, etc.)
e Second Master's degree
e Ed. D
e Ph. D
e JD
e Other (please specify) 
Workplace Incivility and Bullying in the Library: Perception or Reality? 745

10. The following behaviors are often seen as examples of negative behaviors in the workplace. Over the last six months, how often have you been subjected to the following negative acts at work by a co-worker?

\begin{tabular}{|c|c|c|c|c|c|}
\hline & $1=$ never & $2=$ now $\&$ then & $3=$ monthly & $4=$ weekly & $5=$ daily \\
\hline $\begin{array}{l}\text { Someone withholding information which affects your } \\
\text { performance }\end{array}$ & 1 & 1 & 1 & 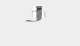 & 1 \\
\hline $\begin{array}{l}\text { Being humiliated or ridiculed in connection with your } \\
\text { work }\end{array}$ & 1) & 1 & 1 & 1 & 1 \\
\hline $\begin{array}{l}\text { Being ordered to do work below your level of } \\
\text { competence }\end{array}$ & 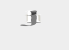 & 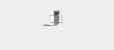 & \pm & 1 & 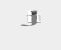 \\
\hline $\begin{array}{l}\text { Having key areas of responsibility removed or replaced } \\
\text { with more trivial or unpleasant tasks }\end{array}$ & 1 & 1 & 1 & 1 & I) \\
\hline Spreading of gossip and rumors about you & I & J & \pm & 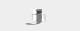 & 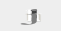 \\
\hline Being ignored or excluded & I) & I & 1 & I) & 1 \\
\hline $\begin{array}{l}\text { Having insulting or offensive remarks made about your } \\
\text { person (i.e. habits and background), your attitudes or your } \\
\text { private life }\end{array}$ & 1 & 1 & 1 & \pm & 1 \\
\hline $\begin{array}{l}\text { Being shouted at or being the target of spontaneous } \\
\text { anger (or rage) }\end{array}$ & II & 1 & 1 & I) & 1 \\
\hline $\begin{array}{l}\text { Intimidating behavior such as finger-pointing, invasion of } \\
\text { personal space, shoving, blocking/barring the way }\end{array}$ & I & 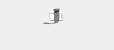 & 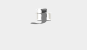 & 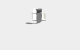 & 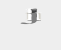 \\
\hline Hints or signals from others that you should quit your job & 1) & II & 1) & 1 & 1) \\
\hline Repeated reminders of your errors or mistakes & 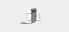 & 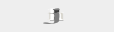 & 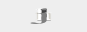 & I & 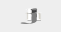 \\
\hline
\end{tabular}

(n)

11. The following behaviors are often seen as examples of negative behaviors in the workplace. Over the last six months, how often have you been subjected to the following negative acts at work by a co-worker?

Being ignored or facing a hostile reaction when you
approach
Persistent criticism of your work and effort
Having your opinions and views ignored
Practical jokes carried out by people you don't get along
with
Being given tasks with unreasonable or impossible
Having allegations or accusations made against you
Excessive monitoring of your work
Pressure not to claim something which by right you are
entitled to (e.g. sick leave, holiday entitlement, travel
expenses)
Being the subject of excessive teasing and sarcasm
Being exposed to an unmanageable workload
Threats of violence or physical abuse or actual abuse

Have you been bullied at work? We define bullying as a situation where one or several individuals persistently over a period of time perceive themselves to be on the receiving end of negative actions from one or several persons, in a situation where the target of bullying has difficulty in defending him or herself against these actions. We will not refer to a one-off incident as bullying.

\section{Using the above definition, please state whether you have been bullied at work over the last six months.}

$$
\begin{aligned}
& \text { 1. No } \\
& \text { 1. Yes, but only rarely } \\
& \text { 1. Yes, now and then } \\
& \text { 1. Yes several times per week } \\
& \text { 1. Yes, almost daily }
\end{aligned}
$$




\section{Have you seen others being subjected to bullying at your workplace during the last six months?}

1. No

1. Yes, but only rarely

1. Yes, now and then

1. Yes several times per week

1. Yes, almost daily

\section{THANK YOU--}

Thank you for completing our survey.

We know your time is valuable, and we appreciate your input.

\section{Notes}

1. WHOBullying Definition, available online at www.who.int/bulletin/volumes/88/6/10-077123/ en/\#R6 [accessed 30 September 2014].

2. Lacey M. Sloan, Tom Matyók, Cathryne L. Schmitz, and Glenda F. Lester Short, "A Story to Tell: Bullying and Mobbing in the Workplace," International Journal of Business and Social Science 1, no. 3 (2010): 87-97; Gary Namie and Ruth Namie, “US Workplace Bullying: Some Basic Considerations and Consultation Interventions," Consulting Psychology Journal: Practice and Research 61, no. 3 (2009): 202.

3. Marie Hutchinson, Margaret Vickers, Debra Jackson, and Lesley Wilkes, "Workplace Bullying in Nursing: Towards a More Critical Organizational Perspective," Nursing Inquiry 13, no. 2 (2006): 118-26, doi:10.1111/j.1440-1800.2006.00314.x.

4. Michael Harvey, Darren Treadway, Joyce Thompson Heames, and Allison Duke, "Bullying in the 21st Century Global Organization: An Ethical Perspective," Journal of Business Ethics 85, no. 1 (2009): 27-40.

5. Zogby 2014 Study, WBI U.S. Workplace Bullying Survey, Workplace Bullying Institute, available online at http://www.workplacebullying.org/wbiresearch/wbi-2014-us-survey/ [accessed 13 September 2016].

6. European Foundation for the Improvement of Living and Working Conditions: Working Time Preferences in Sixteen European Countries, 2002, available online at https://www.eurofound. europa.eu/sites/default/files/ef_files/pubdocs/2002/07/en/1/ef0207en.pdf [accessed 13 September 2016].

7. Reba Leiding, "Mobbing in the Library Workplace: What It Is and How to Prevent It," College E Research Libraries News 71, no. 7 (2010): 364-84; Staale Einarsen, Helge Hoel, and Guy Notelaers, "Measuring Exposure to Bullying and Harassment at Work: Validity, Factor Structure and Psychometric Properties of the Negative Acts Questionnaire- Revised," Work E Stress 23, no. 1 (2009): $24-44$.

8. Virginia Myers, "Confronting Campus Bullies," Aft On Campus (Nov./Dec. 2011), available online at www.aftlocal1904.org/news/AFTOnCampusConfrontingCampusBullies.pdf [accessed 13 August 2014].

9. Stuart Hannabuss, "Bullying at Work," Library Management 19, no. 5/6 (1998): 304-10.

10. Brian R. McAvoy and John Murtagh, "Workplace Bullying," BMJ (Clinical Research Ed.) 326, no. 7393 (Apr. 12, 2003): 776-77, doi:10.1136/bmj.326.7393.776.

11. Pamela Lutgen-Sandvik, Sarah J. Tracy, and Jess K. Alberts, "Burned by Bullying in the American Workplace: Prevalence, Perception, Degree and Impact," Journal of Management Studies 44, no. 6 (2007): 837-62.

12. Eva Gemzøe Mikkelsen and Ståle Einarsen, "Bullying in Danish Work-Life: Prevalence and Health Correlates," European Journal of Work and Organizational Psychology 10, no. 4 (2001): 393-413.

13. Loraleigh Keashly and Steve Harvey, "Emotional Abuse in the Workplace" (Thousand Oaks, Calif.: Sage Publications, 2005).

14. Helge Hoel, Cary L. Cooper, and Brian Faragher, "The Experience of Bullying in Great Britain: The Impact of Organizational Status," European Journal of Work and Organizational Psychology 10, no. 4 (2001): 443-65.

15. Ståle Einarsen, Helge Hoel, Dieter Zapf, and Cary L. Cooper, "The Concept of Bullying and 
Harassment at Work: The European Tradition," in Bullying and Emotional Abuse in the Workplace: International Perspectives in Research and Practice, eds. S. Einarsen, H. Hoel, D. Zapf, and L. Cooper (London: Taylor \& Francis, 2003), 3-30.

16. Lynne M. Andersson and Christine M. Pearson, "Tit for Tat? The Spiraling Effect of Incivility in the Workplace," Academy of Management Review 24, no. 3 (1999): 452-71.

17. Gary Namie, "Workplace Bullying: Escalated Incivility," Ivey Business Journal 68, no. 2 (Nov. 2003): 1-6, available online at http://search.ebscohost.com/login.aspx?direct=true\&db=bu h\&AN=12825960\&site=ehost-live [accessed 30 September 2014].

18. Christine Porath and Christine Pearson, "The Price of Incivility," Harvard Business Review 91, no. $1 / 2$ (2013): 114-21.

19. Ibid., 115.

20. Christine Pearson and Christine Porath, "The Cost of Bad Behavior," Organizational Dynamics 39 (2009): 64-71.

21. Thomas E. Hecker, “Workplace Mobbing: A Discussion for Librarians," Journal of Academic Librarianship 33, no. 4 (2007): 439-45.

22. Raymond R. Leal, "From Collegiality to Confrontation: Faculty-to-Faculty Conflicts," New Directions for Higher Education 1995, no. 92 (1995): 19-25.

23. Loraleigh Keashley and Joel Newman, "Faculty Experiences with Bullying in Higher Education: Causes, Consequences, and Management," Administrative Theory E Praxis 32, no. 1 (2011): 48-70.

24. Darla J. Twale and Barbara M. De Luca, Faculty Incivility: The Rise of the Academic Bully Culture and What We Do about It (San Francisco: Jossey-Bass, 2008).

25. Helge Hoel and Denise Salin, "Organizational Antecedents of Workplace Bullying," in Bullying and Emotional Abuse in the Workplace: International Perspectives in Research and Practice, eds. S. Einarsen, H. Hoel, D. Zapf, and L. Cooper (London: Taylor \& Francis, 2003), 203-18.

26. Leah Plocharczyk, "Managing Conflict and Incivility in Academic Libraries," in Workplace Culture in Academic Libraries: The Early 21st Century, eds. K. Blessinger and P. Hrycaj (Oxford: Chandos, 2013), 307-19.

27. Lacey M. Sloan, Tom Matyók, Cathryne L. Schmitz, and Glenda F. Lester Short, "A Story to Tell: Bullying and Mobbing in the Workplace," International Journal of Business and Social Science 1, no. 3 (2010): 87-97.

28. Susan Hubbs Motin, "Bullying or Mobbing: Is It Happening in Your Academic Library?" ACRL 14th National Conference Proceedings (Chicago: Association for College and Research Libraries, 2009), 291-97; Hecker, “Workplace Mobbing," 439-45; Leiding, "Mobbing in the Library Workplace," 364-84.

29. Motin, "Bullying or Mobbing," 291.

30. Leiding, "Mobbing in the Library Workplace," 364-84.

31. Bonnie A. Osif, "Workplace Bullying," Library Leadership \& Management 24, no. 4 (Fall 2010): 206-12; Bonnie A. Osif, "Incivility," Library Leadership \& Management 24, no. 3 (Summer 2010): 91-97.

32. Steven Bell, "Incivility in the Academic Library" (Jan. 19, 2009), Blog in the ACRLog.

33. Shin Freedman, "Collegiality Matters: Massachusetts Public Higher Education Librarians' Perspective," Journal of Academic Librarianship 38, no. 2 (2012): 108-14.

34. Morten Birkeland Nielsen, "Bullying in Working Groups: The Impact of Leadership," Scandinavian Journal of Psychology 54 (2013): 127-36.

35. Denis Salin, "Ways of Explaining Workplace Bullying: A Review of Enabling, Motivating and Precipitating Structures and Processes in the Work Environment," Human Relations 56, no. 10 (2003): 1213-32.

36. Twale and DeLuca, Faculty Incivility.

37. Denis Salin, "Ways of Explaining Workplace Bullying."

38. Bergen Bullying Research Group, $N A Q$, available online at www.uib.no/en/rg/bbrg/44045/ naq [accessed 9 September 2013]; Stále Einarsen, Helge Hoel, and Guy Notelaers, "Measuring Exposure to Bullying and Harassment at Work: Validity, Factor Structure and Psychometric Properties of the Negative Acts Questionnaire-Revised," Work \& Stress 23, no. 1 (2009): 24-44, doi:0.1080/02678370902815673.

39. Jacob Cohen and Patricia Cohen, Applied Multiple Regression for the Behavioral Sciences (Mahwah, N.J.: Lawrence Erlbaum, 1983).

40. Association for Research Libraries (ARL), Minority Representation in the 2012-2013 ARL Annual Salary Survey, available online at http://www.arl.org/news/arl-news/3370 [accessed 15 May 2016]

41. Maureen Duffy and Len Sperry, Overcoming Mobbing: A Recovery Guide for Workplace Aggression and Bullying (Oxford, U.K.: Oxford University Press, 2014), 15.

42. Ione T. Damasco and Dracine Hodges, "Tenure and Promotion Experiences of Academic 
Librarians of Color," College \& Research Libraries 73, no. 3 (May 2012): 244-301.

43. Helge Hoel and Cary Cooper, Destructive Conflict and Bullying at Work (Manchester, U.K.: Manchester School of Management, 2000).

44. Personal Communication, Julie Otsuka (October 15, 2014).

45. Pauline Schilpzand, Irene De Pater, and Amir Erez, "Workplace Incivility: A Review of the Literature and Agenda for Future Research," Journal of Organizational Behavior 37 (October 2014); Oregon State University Anti-Bullying Policy, available online at http://oregonstate.edu/ombuds/ information-workplace-bully [accessed 15 April 2015]. 